\title{
"Depressive co-morbidity in medical in-patients at the time of hospital discharge and outcome in a Primary Care follow-up. I. Rational and design of the project"
}

\author{
Antonio Lobo, MD* \\ Pedro Saz, MD* \\ Guillermo Marcos, MD** \\ Ricardo Campos, MD* \\ Javier García-Campayo, MD*** \\ Fernando Orozco, MD* \\ M Fe Barcones, B Sc* \\ Antonio Campayo, MD* \\ Aurora Sarasola, MD* \\ and members of the GZEMPP \\ Workgroup
}

* Servicio de Psiquiatría and Departamento de Medicina y Psiquiatría, Facultad de Medicina of the Universidad de Zaragoza and Hospital Clínico Universitario;

${ }^{* *}$ Departamento de Medicina Preventiva y Salud Pública, Facultad de Medicina of the Universidad de Zaragoza and Hospital Clínico Universitario;

***Servicio de Psiquiatría, Hospital Universitario "Miguel Servet". Zaragoza

SPAIN

\footnotetext{
ABSTRACT - Objectives: In a context of a "continuity of care" model in Psychosomatic and Liaison Psychiatry, this study is intended to test, in patients to be discharged from Medicine wards, hypotheses related to a high prevalence of depression and, in particular, its negative outcome at six-months follow-up in Primary Care (PC), specially among the elderly.

Methods:Sample. Consecutive patients aged 18 years or more, hospitalized in Medicine wards were randomly selected for screening at the time of admission. On the bases of a previous study and the expected sampling errors, sample size was estimated in 700 patients (approximately 60\% in geriatric age) for the initial screening, to recruit 75 or
} 
more cases of depression and enough number of control, non-cases without psychiatric morbidity..

Instruments. Standardized, Spanish versions of screening/case-finding instruments COMPRI/INTERMED, Mini-Mental, CAGE and drug screening, Hospital Anxiety and Depression Scale (HADS), Standardized Polyvalent Psychiatric Interview (SPPI). Diagnostic criteria ICD-10 research, medical patients version and DSM-IV-TR (psychiatric); and ICD-9-M; ICHPPC, WONCA (medical). Cumulative Illness Rating Scale (CIRS) (severity of physical condition); SF36 and EuroQol (quality of life); Client Service Receipt Interview (CSRI) (costs).

Procedure. Part I, hospital study: Two-phase screening (lay interviewers: COMPRI/INTERMED at admission; Mini-Mental, CAGE, HADS at the time of discharge; and standardized clinicians: SPPI). CIRS was used to control severity of physical conditions. Part II, follow-up study in PC (six months): Standardized clinicians, blind to the previous phases (HADS and SPPI to both cases and controls). Outcome study: EuroQuol, SF36, CSRI and data on morbidity and mortality, were collected.

Conclusions. To our knowledge, this is the first study using modern epidemiological methods in medical patients to be discharged with co-morbid depression and followed in PC with a "continuity of care" strategy. The final analysis of data should support the design of an evidence-based, intervention study on co-morbid depression.

\section{Introduction and Background}

This study is a new step in the research strategy of the Zaragoza Working Group for Psychiatric and Psychosomatic Morbidity (GZEMPP), in relation to the psychiatric disturbances in general hospital and primary care patients and a new, "continuity of care" strategy close to clinical practice in Psychosomatic/ Liaison Psychiatry. The background of the study may be summarized as follows (Table I).

\section{The research philosophy in a Psychosomatic/ Liaison Psychiatry Unit (PLPU)}

Together with humanistic, holistic foundations, evidence based psychiatric philosophy is one of the cornerstones of Liaison Psychiatry (Lobo 1986, Bronheim et al. 1998), or Psychosomatic Psychiatry, as it might be called in the future in Spain
(Lozano and Lobo 2005). Research completed mainly by liaison psychiatrists has consistently shown that: a) the prevalence of psychiatric morbidity is quite considerable in medical patients (Mayou and Hawton 1986, Lobo 1990, Martucci et al. 1999); b) the detection of this morbidity by medical staff is insufficient, and therefore a high proportion goes untreated (Martucci et al. 1999); and c) negative implications of this untreated co-morbidity have been documented in relation to the prognosis of the medical condition (Koenig et al. 1997), to the patients' quality of life (Beekman et al. 1997) and to the medical costs (Koenig and Kuchibhatla 1999, Saravay et al. 1996). We have previously argued in favour of the epidemiological methods to generate new knowledge in the field (Lobo and Campos 1997). In this context, both depression (Martucci et al. 1999) and delirium (McCusker et al. 2001) are most relevant. We now concentrate on depres- 
Table I

The background of the study

1. The research philosophy in a Psychosomatic/ Liaison Psychiatry Unit (PLPU).

2. The high prevalence of depression in medical patients; the insufficient detection and treatment.

3. The negative implications of untreated depression.

4. Only a small proportion of depressed patients is referred to PLPU's: the multi-center, trans-national European ECLW study.

5. The ECLW strategy to face the challenge of unreferred/ untreated psychiatric morbidity in general hospitals: the mul-ticenter, trans-national European BIOMED projects.

a. The development and implementation of a screening system for the early detection of "complex" patients.

b. An original Quality Assurance system in PLPU.

6. Depressive co-morbidity in medical patients improving with treatment as usual.

7. Depressive co-morbidity in Primary Care patients.

8. The special case of the elderly patients.

9. A continuity of care strategy: Towards an intervention study in Primary Care with depressed patients discharged from Medicine wards.

sion in this project, but delirium will be approached next.

\section{The high prevalence of depression in medical patients; the insufficient detection and treatment}

Depression is one of the commonest psychiatric diagnosis among medical patients with psychiatric co-morbidity. This is classical knowledge in the discipline (Mayou and Hawton 1986, Lesperance et al. 1996). Wells et al. (1988) reported during the ECA study that the prevalence of affective disorder was $9.4 \%-12.9 \%$ in medically ill patients but only $5.8 \%-8.4 \%$ in a matched control group of healthy individuals. Lesperance et al. (1996), and other authors have suggested qualitative differences in the depressive co-morbidity, compared to primarily psychiatric patients (Suh and Gallo 1997). Underdiagnosis, and consequently undertreatment of depression in medical settings has been consistently reported in the international literature (Lobo and Campos 1996).

\section{The negative implications of untreated depression}

The negative implications of depression have been documented in a number of relevant reports: two thirds of general medicine patients continued to be depressed at 3month follow-up (Koenig et al. 1997), and $56 \%$ at 1-year (Fenton et al. 1997). At 2-year follow-up, important dysfunction and quality of life impairment have been described, the level of dysfunction being equal or superior to patients with severe, chronic medical conditions (Hays et al. 1995, Ormel et al. 1999). Predictors of functioning and quality of life have been suggested (Ronalds et al. 1997), but only few rather recent studies control for the physical condition (Koenig and Kuchibhatla 1999). High use of medical services and poor general health (Savoca 1999); and a significant increase in the number of re-admissions to medical wards (Sar- 
avay et al. 1996) has also been documented in depressed patients, as compared to the non-depressed. On the contrary, improvement of depression has been related to decrease in the use of medical services and number of days on sick leave (Von Korff et al. 1992).

The association of depression and increased mortality rate is intriguing, either in general hospital studies (Cole and Bellavance 1997), or in post-discharge follow-up (Lesperance et al. 1996). A systematic review of the literature found that most studies of this type are non-controlled, but half of them reported an increased mortality, particularly in men (Wulsin et al. 1999).

\section{Only a small proportion of depressed patients is referred to PLPU's: the multi-center, trans- national European ECLW study}

The proportion of depressed patients referred for assessment and treatment in PLPU's is quite limited considering the documented morbidity rates. This a well described phenomenon, not limited to this diagnostic group, and one of the main stimuli for Liaison or Psychosomatic Psychiatry (Lipowski 1967, Rundell and Wise 1996, Bronheim et al. 1998). The phenomenon has also been documented by the European Consultation and Liaison Workgroup for General Hospital Psychiatry and Psychosomatics (ECLW) (Huyse et al. 1996), in the first multi-center, multi-national project completed in this field. This study used original standardized methods and assessed close to 15,000 patient interventions by liaison psychiatrists, representing only $1.4 \%$ of general hospital admissions (3\% in Spanish hospitals). This referral rate is quite limited in view of the morbidity documented in the literature. Depression (and delirium) was one of the main diagnostic groups referred. Consequently, one of the conclusions of the study was the need to develop new methods to face the problem of the non-detected, non-referred patients, and depression was one of the main targets. The following paragraphs describe the strategy developed by the ECLW.

\section{The ECLW strategy to face the challenge of unreferred/ untreated psychiatric morbidity in general hospitals: the multi- centre, trans-national European BIOMED projects}

a. The development and implementation of a screening system for the early detection of "complex" patients.

The rational for the Project on the Admission Risk Screening Instrument (ARSI) (Huyse et al. 1997) was the evidence reviewed in previous paragraphs, and the following data: a) the present PLPU's are overwhelmed by clinical work, and have limited ability to cope with an increased rate of referrals. Liaison strategies to improve the ability of non-psychiatrists to detect and treat psychiatric morbidity have been suggested, but also the possibility to design and implement new screening and case finding strategies to decide on priorities about intervention needs (Huyse et al. 1997); and b) patients referred to PLPU's are often "complex" and, for example, the ECLW study documented that length of hospital stay is twice or three times higher among patients referred to PLPU's. (Huyse et al. 1996).

Consequently, a trans-national Project was designed to develop an original system to detect at admission precisely the "complex" patients (Huyse et al. 1997). Follow- 
ing this, a short method based on the previous one has been developed (COMPRI), as well as a special interview to be administered by nurses, INTERMED (Huyse et al. 1999). INTERMED was also developed to provide a model to communicate these potential problems to the medical staff. While this line of research is promising and productive, the working group keeps other research strategies to face the psychiatric morbidity, and specifically depression. Quality improvement research is one such strategy.

\section{b. An original Quality Assurance system in PLPU.}

One of the methods to face care needs is the modern approach to improve quality of care, but no relevant experience in Liaison Psychiatry existed previously. Therefore, the ECLW workgroup started an ambitious, trans-national European Project, with promising results (Herzog et al. 1995). The study was also completed in a multi-center Project in Spain, (Lobo et al. 2000, Valdés et al. 2000), "continuity of care" related to Primary Care being a priority in the University Hospital of Zaragoza.

\section{A proportion of depressive co- morbidity in medical patients improves with treatment as usual}

Previous studies in our hospital documented that a proportion of psychiatric morbidity in medical wards, including depression, improves with "treatment as usual" before hospital discharge (Pérez-Echeverría 1985). This has been suggested in few other studies (Rundell and Wise 1996). Therefore, in a "continuity of care" strategy, we considered particularly relevant to identify the patients still depressed at the time of hospital discharge, and the factors influencing this morbidity, since this may have direct implications for planning intervention strategies.

\section{Depressive co-morbidity in primary care patients}

In support of pioneering observations by authors such as Goldberg and Blackwell (1970), a review before this study was initiated documented that the prevalence of major depression in Primary Care, in different countries, ranged from $4.8 \%$ to $13.5 \%$, and minor depression from $3.4 \%$ to $6.4 \%$ (Lobo and Campos 1996). Furthermore, this review included important studies, such as the large, multi-center, multinacional study of WHO (Ustün 1994), documenting insufficient detection of depression in PC. Similarly, studies completed in this setting, including the studies by the WHO have documented the negative consequences of depression (Simon et al. 1999). These consequences include social and vocational dysfunction; negative perception of own health and worse prognosis (Ormel and Costa e Silva 1995); an increased use of medical services (Manning and Wells 1992) and medical costs (Von Korff et al. 1992). The WHO study also documented a doseresponse relationship between severity of depression and disability (Sartorius et al. 1993), and multiple regression models of analysis suggested that disability was more related to psychiatric disturbance than to physical disturbance (Ustün and Sartorius 1995). Somatization has often been studied in relation to depression in this setting, but there are not many studies on co-morbidity, and specifically on depressive and somatic co-morbidity (Kisely and Goldberg 1996).

We previously completed the Zaragoza Study of psychiatric morbidity in PC (Lobo 
et al. 1994), a two-phase screening with standardized instruments, including the Standardized Polyvalent Psychiatric Interview o SPPI (Lobo et al. 1993), in a representative sample of patients (8 PC centres, 1,559 patients) with a new inception episode: the prevalence of psychiatric morbidity was $27 \%$ and approximately one third the cases were diagnosed as depressed (ICD-10 and DSM-IV diagnostic criteria). Unrecognized morbidity, documented with several methods was also considerable. Somatic and psychiatric co-morbidity was a rather frequent phenomenon in this study: $47.3 \%$ of psychiatric cases (depression was one of the main diagnostic subgroups) had a co-morbid, but independent somatic condition, and $7.1 \%$ had a psychiatric disorder secondary to the somatic condition (adjustment, depression and/ or anxiety) according to Bridges and Goldberg's criteria (validity in our setting, kappa=0'87) (García-Campayo et al. 1996). A proportion of the comorbidity cases had been admitted to general hospitals wards. In the light of these findings, we now consider relevant the study of this type of depressive co-morbidity in PC.

\section{The special case of the elderly patients}

A rather high prevalence of major depression has also been observed among the elderly, both in primary care studies (Kukull et al. 1986), including the WHO studies (Ustün and Sartorius 1995) and in hospital studies (Koenig et al. 1997, Koening and Kuchibhatla 1999). The prevalence rates might be even higher than in adult nonelderly patients, but this hypothesis has not been adequately tested. It may have important consequences in view of both, the high proportion of patients of this age group admitted to general hospitals and the negative implications of depression reported in elderly patients (Cole and Bellevance 1997, Williamson and Schulz 1992). In this subgroup, and controlling for age, functional status and severity of the medical condition, depressed patients had a length of hospital stay almost double than the non-depressed (Koenig et al. 1989). Similarly, a significantly higher number of stays in residencies and of medical visits has been documented in the depressed patients (Koenig and Kuchibhatla 1999).

The association of depression and increased mortality rate is particularly intriguing among the elderly (Wulsin et al. 1999), either in general hospital studies (Cole and Bellavance 1997), or in non-hospitalized patients (Lesperance et al. 1996). We have also shown in a representative sample of the elderly community in Zaragoza the association of depression and death, after controlling for gender, age and the presence of a somatic condition (O.R.= 3.0) (Saz et al. 1999).

\section{A continuity of care strategy: Towards an intervention study in Primary Care, in depressed patients discharged from Medicine wards}

Some rather recent studies have addressed the issue of intervention studies in depression in medical settings. In a classical review, Katon and Gonzales (1994) concluded that interventions in depression in Primary Care had in general favourable results, but models of intervention were different and methodological problems prevented solid conclusions. In a similar setting, the study of Katzelnick et al. (1997) reported an improvement in symptoms, quality of life (SF- 
36), days at work and cost reduction. Malt $e t$ al. (1999) documented in a naturalistic study the efficacy of uncomplicated, combined psychological and pharmacological treatments. Tiemens et al. (1999) suggested that 20 hours training of primary care physicians improved their ability to detect and treat non-chronic depressions, but not the chronic or recurrent ones; and von Korff et al. (1998) suggested that collaborative treatment ("liaison" type) in patients with major depressions, but not minor depressions, was cost- effective. Shmuely et al. (2001) have reported the efficacy of treatment in elderly patients. On the contrary, there is much less evidence related to interventions in general hospital settings, although Slaets et al. (1997) have reported favourable results of a collaborative strategy of geriatricians and psychiatrists. In particular, we are not aware of intervention studies by liaison psychiatrists in depressed patients identified in medical wards and followed-up after discharge.

Table II

The rational for the research project

1. Depressive co-morbidity in hospitalized medical patients with potentially severe physical conditions is an issue of public health dimension, in view of a documented high prevalence and negative implications. However, there is not enough coverage in some areas of previous research.

2. This is the first study designed with a "continuity of care" strategy:

a. It identifies depression at the time of hospital discharge, to adequately address the issue of depression not improving in the hospital with "treatment as usual".

b. Depressed patients and controls are followed-up in Primary Care (PC).

3. The study includes methodological aspects not always covered in previous research:

a. Representative sample and sampling errors are addressed.

b. Contrary to some previous research:

i. The follow-up period is considered to be sufficient to test the main hypotheses.

ii. It addresses the issue of physical co-morbidity in depression in PC patients.

c. Adequate statistical power is expected to verify the main hypotheses about a negative outcome of depression in relation to control patients without psychiatric co-morbidity; and about factors influencing a negative outcome.

4. There are not previous studies in this setting adequately addressing the comparison between the elderly and the adult non-elderly.

5. The study should generate the bases to design an intervention study, with a psychosomatic/liaison psychiatry strategy of continuity of care, built on the specific data of this research.

6 . The study is intended to provide a model to design a future, multi-center study with a nation-wide dimension in Spain.

\section{Summary: the rational for a new study}

A new review of the literature suggests that the original objectives and design of the research project are still valid. Recent reports, including descriptive and epidemiological studies in medical populations tend to confirm previous findings and suggest that depression continues to be one of the commonest psychiatric diagnosis among medical patients (Meyer et al. 2002). Similarly, the latest research tends to confirm the negative implications of untreated depression (Bech et al. 2003, Loughlin 2004, Harpole et al. 2005). Diagnostic difficulties, 
including the differentiation of delirium and depression (Schneider et al. 2000) have been addressed, but there is no evidence that the problem of both, underdetection and undertreatment of affective disorders in medical settings has improved in the last few years. New studies confirm the potential of intervention strategies in depression in medical settings (Noel et al. 2004, Charney et al. 2003, Lyness et al. 2004, Wells et al. 2004). However, intervention designs would be more convincing if they were based on specific data in the index population.

Therefore, this review lays the ground for a new study on the depressive co-morbidity observed in medical in-patients at the time of hospital discharge, and the rational is summarized in table 2. This new study is intended to improve previous methodological shortcomings; to introduce new aspects, such as the comparison between the elderly and the non-elderly adults. In particular, the study is intended to eventually support a "continuity of care" strategy in liaison psychiatry: the results of this research should provide the data to design an intervention study on depression identified in patients hospitalized in medical wards and then followed-up in primary care. Should the feasibility of this study be demonstrated, the research could be expanded to multi-centre studies, including studies with a European dimension.

\section{Objectives and Hypotheses}

The specific objectives in this project include:

A. Part I, a baseline study, at the time of hospital discharge:
1. To document the prevalence of depression in patients admitted to Medicine wards; the psychopathological characteristics and diagnostic distribution of different types of depression; in particular, the characteristics of depression in the elderly, and differences with adult non-elderly patients. 2. To document: a. The validity of the COMPRI/INTERMED system to detect "complex patients" at the time of hospital admission; b. The usefulness of a simple screening of depression that might be implemented by internists.

B. Part II, a 6-month follow-up study in Primary Care of patients depressed at the time of discharge, to document:

3. The chronicity index of depression; the quality of life impairment; the use and costs of medical services. 4 . The differences in the above parameters between geriatric and non-geriatric adult, depressed patients. 5 . The mortality rates.

C. Secondary objectives were to design an intervention study in depressed patients on the bases of results analyzed in this project.

The specific, operational hypotheses were:

A. Baseline, hospital study.

1. Once the exclusion criteria (patients with a severe physical condition, etc.) are implemented, the prevalence of depression at the time of discharge from Medicine wards will be approximately 20\%. 2. More than half the depressions will be major (DSM-IV criteria). 3. Family history of depression will be less frequent in these medical cases than in cases of depression reported in primarily psychiatric patients. 4. The COMPRI/ INTERMED method will be able to detect at the time of hospital admission at least $50 \%$ of patients depressed at the time of hospital dis- 
charge. 5. A simple screening (Mini-Mental, CAGE; HADS) is valid to detect before hospital discharge the depressed patients with a negative outcome.

\section{B. Follow up, Primary Care study:}

In the patients depressed at the time of hospital discharge:

6. The chronicity index (proportion of patients still depressed at follow-up) will be higher than $50 \%$. 7. Compared to nondepressed patients, after controlling for severity of the somatic condition: a) the impairment in quality of life will be significantly higher; b) the excess use of medical services will be higher than $100 \%$; c) the excess of medical costs will be higher than $20 \%$; d) the mortality rate will be significantly higher, and 2 years after discharge will be higher than $100 \%$. 8. In geriatric depressed patients (65+ years), compared to adult, nongeriatric depressed patients, the following parameter will be significantly higher/ more frequent: a) the prevalence of depression; and of "major" depression; b) the "chronicity" index of depression; c) the quality of life impairment; d) the use of medical services; and the costs of medical services; e) and the mortality rate.

\section{Methods}

\section{Design of the Study}

This is a longitudinal study, randomized, blind to the observer, comparative between depressed medical patients and patients without psychiatric co-morbidity. It includes Part I, a baseline, hospital study; and Part II, a follow-up in Primary Care (Figure 1 ). The study was conducted in two Medicine wards at the Hospital Clínico Universi- tario in Zaragoza, Spain. This is a rather typical University and National Health System hospital with regional functions, covering the Health Area III in Zaragoza, a city with 650,000 inhabitants. For specific pathologies and/or procedures, such as a full range transplant program, the hospital also has supraregional functions.

\section{Sampling}

Consecutive patients admitted to the ward, both males and females, aged 18 or more years, were randomly selected for screening at the time of admission. For logistical reasons, to allow the programmed follow-up in Primary Care, only patients living in the hospital Health Area (which includes one third the population in the city of Zaragoza) were selected. The initial, exclusion criteria were: a) patients severely ill or who had died at the time of being invited to participate; b) evidence of a previous psychiatric condition; c) language difficulties making impossible the assessment; d) refusals to participate; e) patients admitted for special procedures (usually with non-severe conditions) and short stays (less than 4 days) or patients re-admitted during the study period.

The following considerations were taken into account in relation to sampling size:

1. The principal hypotheses referred to quality of life and medical costs in depressed, compared to non-depressed controls. 2. It was intended to detect differences of $20 \%$ or more in medical costs, with a type I error of $5 \%$ and statistical power of $90 \%$. 3. Losses at 6-month follow-up were considered, due to mortality, refusals and not found patients, which are common in the elderly. 4. Consequently, an initial sample of 75-100 cases of depression was esti- 


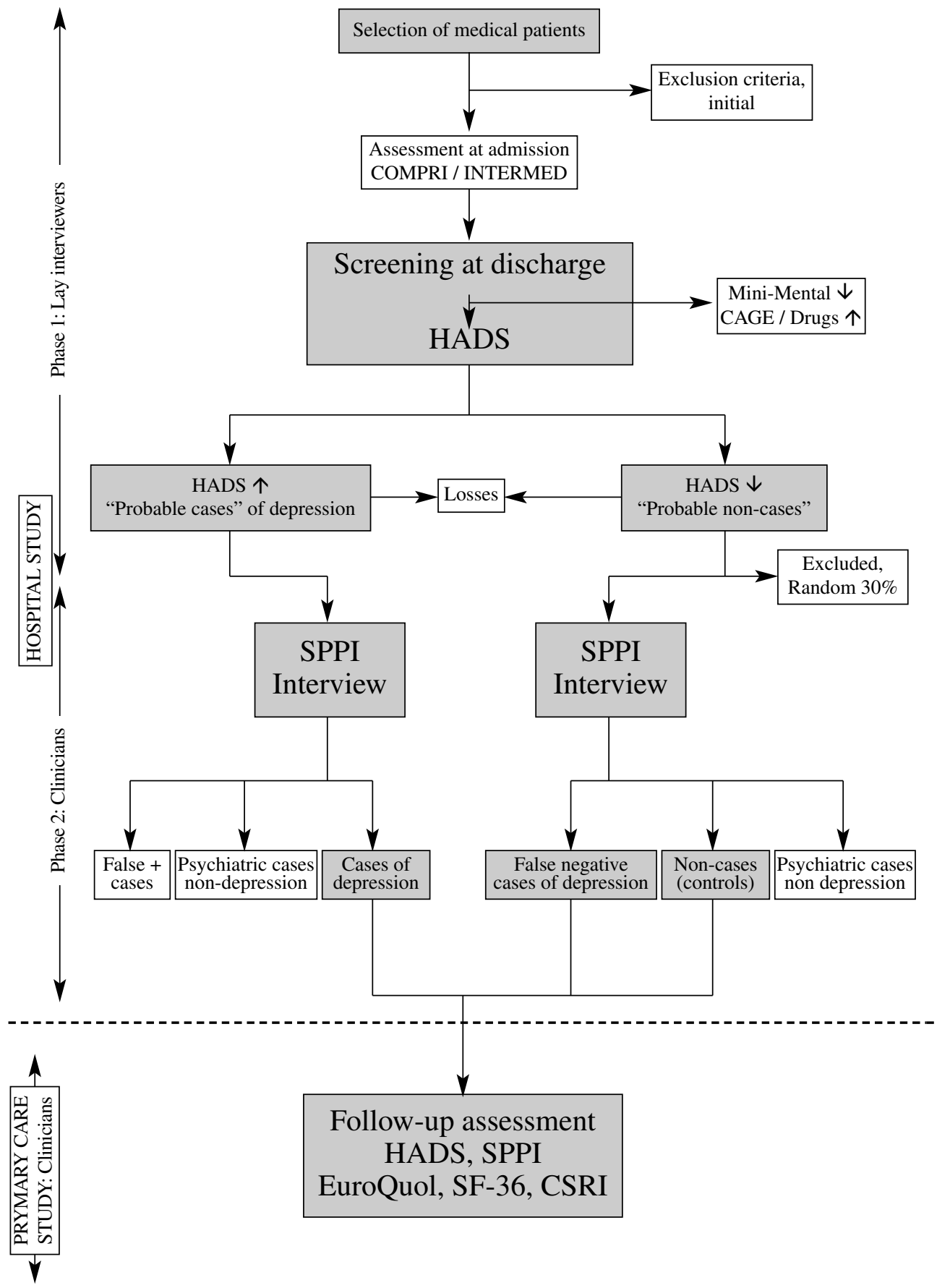

Figure 1. The design of the study. 
mated, and a higher number of non-cases to assure comparability. On the bases of a previous study in Manchester (Creed et al. 2002), it was estimated that sample size for the initial recruitment should be approximately 700 patients.

\section{Instruments}

Socio-demographic variables (age, sex, marital status, living situation, working situation) were recorded following common procedures in medical research, and the following instruments were used:

Hospital Anxiety and Depression Scale (HADS), a self-administered scale with seven questions relating to anxiety and seven to depression. It is less biased than other depression scales towards symptoms resulting from concurrent medical conditions, as it does not contain items referring to physical symptoms (Spinhoven et al. 1997, Zigmond and Snaith 1983). The Spanish validated version (Tejero et al. 1986), which shows similar efficiency than the original version, has been used in this study. The scores are totalled to give a depression score and an anxiety score (range 0-21). Since the threshold indicating a significant clinical problem may be different depending on the medical sample, a pilot study was previously completed, and a cut-off point 10/11 on the depression scale was selected for this particular study.

Examen Cognoscitivo Mini-Mental (MiniMental), the official Spanish version of Mini-Mental Status Examination (MMSE) (Folstein et al. 1975), the instrument for the screening of cognitive deficits in more widespread use internationally. Our group completed the first validation out of the USA (Lobo et al. 1979). More recently, a revalidation in a representative, community sample, documented very similar population norms to the American version (Lobo et al. 1999). The standard threshold point 23/24 was used in this study.

COMPRI/INTERMED. This is a method developed by members of the ECLW workgroup on the basis of a series of risk factors for care complexity. COMPRI (Complexity of Care PRediction Instrument) is a short instrument to detect patients in need of complex care needs at admission to a general hospital. Its feasibility, reliability and validity has been previously documented (Huyse et al. 2001). INTERMED is an observer rated instrument that classifies information from a medical history-taking into four domains related to bio-psychosocial and health care aspects of disease (Huyse et al. 1999). In each of the four domains five variables are rated 0-3 according to a manual with clinical anchor points, resulting in a potential score range of 0-60. Scoring is based on the patient interview and a review of the medical chart. Both the reliability and validity of this instrument have been reported, and a trained nurse can reliably rate it. The standard cut off score of 20/21, and the Spanish version of INTERMED previously standardized by the authors (Lobo et al. 2003) were used in this study.

CAGE Scale, the instrument developed by Mayfield et al. (1974) and Ewing (1984) and widely used for the screening of alcohol problems. It also has an Spanish validated version. The threshold used in this study to consider a "probable case" of alcoholism was $1 / 2$, in correspondence with the literature. The use of other drugs was screened with a similar questionnaire, which was previously standardized in a pilot study (Lobo et al. 1994). 
Cumulative Illness Rating Scale (CIRS) (Linn et al. 1968), an instrument designed to assess organic impairment in a reliable, brief, and easy-to-use way, which has been successfully tested in medical inpatients. The validated, Spanish version has been used in this study (Bulbena et al. 1996). It evaluates 13 categories or systems (heart, vascular, respiratory systems, etc.) each one scored from 0 (no impairment) to 4 (highest possible impairment). A careful training of interviewers was previously completed to follow the recommendations of the Spanish author. For the purpose of this study, the severity index based on the total score on the questionnaire was used.

Health Survey SF-36 (Ware and Sherbourne 1992, Aaronson et al. 1992), a brief, self-administered questionnaire intended to be a general measure to capture quality of life as well as whether an individual is healthy or not. The questionnaire is made up of 8 scales, covering the ability to function and complete everyday activities, including physical and social activities; they also capture well-being, such as energy or fatigue and mental health. It has 36 items and the score range is $0-100$, the highest scores meaning a good health. The SF-36 has considerable potential to document the results of medical interventions. The reliability and validity of both, the original version, and the Spanish version used in this study (Alonso et al. 1995, Prieto et al. 1997) have been adequately documented.

Quality of Life (EuroQol), also a short, self-administered instrument designed by the EuroQol group (1990) which intends to be a generic measure of health status. It defines health in terms of 5 dimensions (mobility, self care, usual activities, pain or discomfort, and anxiety or depression), that may be combined to define a total of 243 health states. Respondents record the extent of their problem in each of the five dimensions and then record the perception of their overall health on a visual analogue scale ( 0 denoting the worst imaginable health state and 100 denoting the best imaginable health state). The validity and reliability of the questionnaire have been tested in a range of patient groups (Brooks 1996). Similarly, the reliability and validity of the Spanish version used in this study have been previously documented (Badía et al. 1996).

Client Service Receipt Interview (CSRI). This is a questionnaire intended to document variables of medical care, including duration of the "index" hospitalization, number and duration of subsequent admissions, out-patient visits, and visits to the emergency room; visits by the familiy physician both in a health center and domiciliary; periods of sick leave; losses of income and hobbies due to illness; costs of informal carers and other medical costs. This questionnaire has been used in the Manchester study (Creed et al. 2002), and a pilot, validity study was completed locally previous to the main study.

Standardized Polivalent Psychiatric Interview, SPPI. This is a structured interview developed by our research group primarily for assessing medical patients (Lobo et al. 1993). It was built on the Clinical Interview Schedule and is intended to evaluate individuals in a multi-axial schema: psychopathology, including duration and severity of disorder; somatic disturbance; social problems and social supports; and pre-morbid personality, with special emphasis on 'neuroticism'. The SPPI generates enough information to allow the use of different research diagnostic criteria, including DSM-IV, ICD-10 and Goldberg's criteria of 'attribution' of somatic symptoms and 'relationships between psychiatric and physical disorder'. At the end of the interview, a med- 
ical diagnosis is also coded. Finally, this interview also includes a section related to recommended treatment. The instrument fulfils standards of feasibility, reliability and validity, including procedural validity, which allows its use by researchers such as standardized primary care physicians.

Psychiatric diagnostic criteria. Psychiatric cases have been diagnosed according to both, the Diagnostic and Statistical Manual of the American Psychiatric Association (DSM-IV-TR, APA 2000) and the International Classification of Diseases, 10th Edition (ICD-10, WHO 1992). We have used the modified version for general hospital medical patients completed by the European, ECLW Wokgroup (Malt et al. 1999), wich included researchers in the present study.

Somatic diagnostic criteria. The medical condition has been diagnosed according to both, the International Classification of Diseases, 9th Edition (ICD-9-M), and the International Classification of Diseases for Primary Care (ICHPPC, WONCA, 1985).

\section{Inclusion and Exclusion Criteria}

The following inclusion and exclusion criteria were used for the group of depressed patients:

\section{Inclusion criteria:}

- Criteria for "caseness" in the SPPI (global score 2+).

- Diagnosis of depression in any of the following ICD-10 categories: F06.3 ( "organic depression"); F31, 32, 33, 34.1, 38, 39 (affective disturbance ); F43 (adaptive disturbance).- For a diagnosis of "major depression" in this study, only patients scoring $3+$ in the SPPI were considered (moder- ate/ severe intensity); for the categories F34.1 y F43 only patients scoring 4 in the SPPI were considered.

\section{Exclusion criteria:}

- Any type of psychiatric co-morbidity with the following ICD-10 categories: dementia, delirium, other "organic" disturbances different from depression (F06); substance abuse disturbances (F10-F19), schizophrenia group (F20-F29), mental retardation (F70-F79).

- Co-morbidity with other ICD-10 psychiatric categories (neurosis, personality disturbance, etc.) only when these were the primary diagnosis.

- Non-compliance, refusal, etc.

Criteria for "chronicity" of depression: A depression was considered to be "chronic" when the patient persisted to be a case of depression at the 6-month follow-up assessment.

Among the patients admitted to the study wards, the following inclusion and exclusion criteria were used for the group of controls, non-cases.

\section{Inclusion criteria:}

- Patients recruited with the previous procedure, having no clinically relevant psychpathology (SPPI <2), and not fulfilling exclusion criteria.

\section{Exclusion criteria:}

- Criteria for "caseness" in the SPPI (global score 2+).

- Specifically, to fulfil diagnostic criteria for depression in any of the categories in the previous section:

- Non-compliance, refusals, etc., 


\section{Procedure}

\section{A. Baseline, hospital study}

\section{Selection of patients.}

The patients were selected during the field study period (February, 2002 - June, 2004) according to the criteria described in the sampling section. The patients were asked to sign a written informed consent according to Spanish laws, and their sociodemographic information was collected.

2. Assessment with the COMPRI/ INTERMED method.

Following that, in a subsample of patients, a previously standardized, research nurse reviewed the medical chart, administered the COMPRI and then conducted the patient interview necessary to score the INTERMED, all in the first three days after admission (Figure 1).

3. Screening at the time of hospital discharge

a. Three days before discharge, once the internists informed of their decision, was considered an appropriate time for the second assessment of patients. The participating individuals were again invited and were then assessed by research workers, "lay interviewers" previously trained and standardized, with the Mini-Mental and CAGE and drug questionnaires. The patients considered to be probable cases of cognitive deficits (Mini-Mental) and/or use of substances (CAGE) on the bases of scores on one or both instruments were excluded. The remaining individuals were then assessed with the HADS, to identify probable cases of depression and probable non-cases.

b. The "probable cases" of depression were then examined in the following 48 hours by clinicians standardized in the use of the SPPI interview, in such a way that false positive cases of depression would be identified and separated out of the sample of real cases of depression. Similarly, the "probable non-cases" were to be examined with the SPPI, to identify both, false negative cases of depression and controls without psychiatric morbidity. However, for logistical reasons, it was decided to select for this examination, in a random way, $70 \%$ (approximately) of the probable non-cases. The research clinicians were standardized psychiatrists in training (residents), but also standardized family physicians, since we have previously documented the procedural validity of the SPPI (Lobo et al. 1993). For a diagnosis of a case of depression or, on the contrary, a confirmation as a control; and to confirm that the patients fulfilled inclusion and exclusion criteria, the interviewers were supervised by senior research psychiatrists, expert in the use of the SPPI in this setting.

\section{Post-discharge collection of data.}

After the patients' discharge, independent research workers, blind to the previous results, reviewed the discharge medical reports and collected information from the hospital database (MBDS). Based on this information, the CIRS was scored, and information about care complexity variables, such as length of hospital stay, number of medical diagnoses, number of ancillary procedures, etc., was collected.

\section{B. Follow-up study in Primary Care}

A six-month Primary Care follow-up was then completed. Both, depressed patients and the control patients identified in the baseline study were invited to participate through an individually signed letter. Participating patients were assessed in their health care center by standardized research clinicians, different from and blind to the results of the interviewers participating in the pre- 
vious phases of the study. They administered the HADS to all participating patients and examined them with the SPPI structured interview. The psychiatric cases were again diagnosed according to both, DSMIV-TR and ICD-10, medical patients version (Malt et al. 1996). The clinicians also collected information about the somatic condition, the medical information coming directly from the patients, but also from data collected by the primary care physicians in charge. The CSRI was completed according to this information and ICD-9-CM/ WONCA criteria were used for the medical diagnosis. Furthermore, the EuroQual and SF36 were also administered to all patients.

A minimum medical protocol was completed in cases of death at follow-up, at least by means of a telephone call to the patients' family.

\section{Statistical analysis}

The SPSS package will be used for statistical analysis. Conventional analyses will be completed, and both parametric and nonparametric methods will be used for univariate calculations in dependence of type of distribution. Continuous variables will be presented with means and standard errors, with adjustments when appropriate (severity of the medical condition, etc.). Exploratory methods and analysis of multiple correspondence have been programmed for a preliminary view of interrelations between variables.

Multivariate analysis will be conducted to identify independent variables contributing, for example, in quality of life or medical costs variables. The following variables will enter the multivariate analysis to identify and model factors at the time of study recruitment, contributing independently to quality of life and costs at follow-up: sociodemographic (age, gender, social class, etc.); medical diagnosis group; severity of the medical condition (CIRS); and psychiatric diagnosis.

\section{Ethical Procedures}

Informed consent was requested for all potential participants in the study, following standard procedures recommended by the local Ethical Committee, the Helsinki Convention, and the Madrid Declaration of the World Psychiatric Association. The internists were notified in cases of severe depression, particularly in cases of suicidal ideation, with the recommendation to refer the patient to a psychiatrist. Similarly, the primary care physician was also notified when severe cases of depression were detected at followup.

\section{Discussion}

\section{Relevance of the study}

The relevance of this study is supported by the expected size and negative implications of depressive co-morbidity in hospitalized medical patients, which may have public health consequences (Lobo 1990). There are abundant, previous studies of depression in medical wards, documenting that a considerable proportion of this co-morbidity goes both, undetected and untreated (Mayou and Hawton 1986, Rodin et al. 2005). While most studies are cross-sectional, some have followed-up hospital patients after discharge (Koenig and Kuchibhatla 1999). However, this is the first study that we are aware of that is designed with a "continuity of care", Liaison Psychiatry strategy. Empirical studies in Liaison Psychiatry tend to support the belief that psychiatrists in general hospital setting often act as "fire-squads", primarily taking care of 
acute referrals from medical services, without an adequate planning of interventions based on the epidemiological evidence (Huyse et al. 1996). The main objectives in this study are to confirm hypotheses about the high prevalence and negative outcome of depressive co-morbidity in medical patients discharged from general hospital wards and followed-up in Primary Care. However, the study is also intended to document the validity of a simple screening that might be used by internists to detect the depressed patients with a negative outcome; and to build on the data collected in this study the design of the next, intervention study to improve the outcome of the depressed patients. In this way, an evidencebased, "continuity of care" strategy to be implemented by liaison psychiatrists might be developed to face the challenge of depressive co-morbidity in medical settings.

It might be argued that early detection of depression, at the time of hospital admission, may be more appropriate, since it could possibly lead to an early intervention to prevent, for example, an increased length of stay (Smith et al. 2005). However, we have decided to detect depression at the time of discharge, and the rational may be summarized as follows: a) a proportion of patients improve during hospital stay with "treatment as usual" by internists (PérezEcheverría 1985); b) mean stay in our hospitals is about 8.5 days in medical wards (H.C.U. 2003), a very short period for an effective and lasting intervention; c) in the attempt to develop and to implement a strategy close to clinical practice in rather understaffed, present-day PLPU's, it seems appropriate to concentrate efforts in patients with a high probability of a negative outcome, such as in the "complex" patients model of Huyse et al. (1997); and d) a "continuity of care" strategy would allow liaison psychiatrists to influence the post-discharge treatment and/or referral by PC physicians. Should the main hypotheses, related to a negative outcome at follow-up be verified, a strong support may come for an intervention study in this subgroup of depressed patients.

The study of depression in elderly medical patients is also emphasized here, and the rational may be summarized as follows: a) a high proportion of patients in old age are expected in general hospitals in Western countries such as Spain, and the preliminary analysis in this particular study tends to confirm this expectation (Lobo et al. 2005); b) we hypothesize that the expected negative outcome of depression will be more pronounced in the elderly, certainly in relation to mortality (Saz et al. 1999); and c) the comparison between the elderly and nonelderly adult medical patients is an underesearched area, and may provide important clues about the specificity of some issues for the old age, including the psychopathological characteristics of depression.

\section{Methods}

We consider this study incorporates methodological aspects considered to be important in present day epidemiological research. The size of the sample initially selected $(n=709)$ is quite considerable, larger than in most studies of depression in medical wards, and representative of patients seen in Medicine wards in our particular hospital, which is a rather standard National Health System (NHS) hospital covering a geographic Health Area. A second advantage is that the calculations of sampling size and sampling error should provide adequate statistical power for the testing of the main hypotheses; and the fol- 
low-up period is also considered to be sufficient to test the main hypotheses.

While the main hypotheses relate to the outcome of depression, the advantage of describing the psychopathology in a rather typical sample of medical patients should not be minimized (Suh and Gallo 1997). In relation to this, it might be argued that some symptoms of depression, in particular the somatic symptoms are in fact manifestations of a physical disturbance. This is a common critique and concern in psychiatric studies among medical patients. However, we have been very careful about the assessment instruments selected. First, we have used the HADS, which is an instrument designed for use in medical patients and concentrates on the non-physical symptoms (Zigmond and Snaith 1983); second, we selected the SPPI interview, which was specifically designed for use in medical patients (Lobo et al. 1993); and third, we use ICD-10 diagnostic criteria, modified for use in general hospital patients (Malt et al. 1999). Therefore, we are confident that we could provide a good description of the psychopathology of depression in patients with severe physical conditions.

\section{Other limitations}

Potential limitations in this study should also be considered. First, sample size might be rather short to study some subgroups of patients, related to types of depression, or to age subgroups. Second, while our particular hospital is a rather standard NHS hospital, we can only argue about the representativeness of the sample in a particular Health Area. In relation to both these limitations, we are now involved in a large, multi-center, nation-wide study, which has been designed on the bases of the experience in Zaragoza and should provide adequate sample size and national representativity (Lobo et al. 2005).

Other limitations relate to the follow-up period, since a six-month follow-up may be insufficient to test the hypothesis related to a higher mortality among the depressed. It is for this reason that the design of the study has considered a 2-year follow-up (at least with a telephone interview with the family and/or an administrative control) for this particular hypothesis. We might also find difficulties in controlling for the physical condition. While we used the CIRS, a standardized, valid instrument for measure severity (Linn et al. 1968, Bulbena et al. 1996), we expect to find a considerable number of different medical conditions that might influence in different ways the psychiatric co-morbidity.

\section{Acknowledgements}

Supported by grant PM99-0084 from the Dirección General de Enseñanza Superior e Investigación Científica and by grant RTIC G03-128 from the Fondo de Investigación Sanitaria, Minsterio de Sanidad y Consumo, Madrid, Spain.

The following researchers of the GZEMPP Workgroup are also authors in this paper: Aguirre JA, Gil C, Lobo-Escolar A, Arnal P, Cazcarra RA, González I, Guiote I, Ibáñez M, Lobo-Escolar E, Martínez B, , Pascual A, Tomás L, Zapata $\mathrm{C}$; and the following collaborated in the design of the project: Bierge A, Frisas O, González J, Lalana JM, Martínez A, Montón C, Ríos J. 


\section{References}

Alonso J, Prieto L, Antó JM. La versión española del SF-36 Health Survey (Cuestionario de Salud SF-36): un instrumento para la medida de los resultados clínicos. Med Clin 1995; 104: 771-776.

Aaronson NK, Acquadro C, Alonso J et al. International Quality of Life Assessment (IQOLA) Project. Qual Life Res 1992; 1:349-51.

American Psychiatric Association. Diagnostic and Statistical Manual of Mental Disorders, 4th Edition, Text Revision (DSM IV TR). Washington, DC: American Psychiatric Association; 2000.

Badía X, Díaz-Prieto A, Rué M et al. Measuring health and health state preferences among critically ill. Intensive Care Med 1996; 22: 1379-1384.

Bech P, Lucas R, Amir M et al. Association between clinically depressed subgroups, type of treatment and patient retention in the LIDO study. Psychol Med 2003; 33(6): 1051-1059.

Beekman ATF, Deeg DJH, Braam AW et al. Consequences of major and minor depression in later life: a study of disability, well-being and service utilization. Psychol Med 1997; 27(6): 1397-1409.

Bronheim H, Fulop G, Kunkel EJ et al. The Academy of Psychosomatic Medicine Practice Guidelines for psychiatric consultation in the general medical setting. Psychosomatics 1998; 39: S8-S30.

Brooks R. EuroQoL: the current state of play. Health Policy 1996; 37(1):53-72.

Bulbena A, Jaúregui JV, Zabalo MJ. Índice Acumulativo de Enfermedad. Adaptación castellana del Cummulative Illness Rating Scale en población psicogeriátrica. Revista Gerontológica 1996; 6: 313-318.

Charney DS, Reynolds CF 3rd, Lewis L et al. Depression and Bipolar Support Alliance consensus statement on the unmet needs in diagnosis and treatment of mood disorders in late life. Arch Gen Psychiatry 2003; 60(7): 664672 .

Cole MG, Bellavance F. Depression in elderly medical inpatients: a meta-analysis of outcomes. Can Med Assoc J 1997; 157(8): 1055-1060.

Creed F, Morgan R, Fiddler M et al. Depression and anxiety impair health-related quality of life and are associated with increased costs in general medical inpatients. Psychosomatics 2002; 43(4):302-309.

Ewing JA. Detecting alcoholism: the CAGE questionnaire. JAMA 1984; 252: 1905-1907.
Fenton FR, Cole MG, Engelsmann F et al. Depression in older medical inpatients: one-year course and outcome. Int J Geriatr Psychiatry 1997; 12(3): 389-394.

Folstein MF, Folstein SE, McHugh PR. Mini-Mental State: a practical method for grading the cognitive state of patients for the clinician. J Psychiatr Res 1975; 12(3): 189198.

García-Campayo J, Campos R, Marcos G et al: Somatization in Primary Care in Spain. II: Differences between Somatizers and Psychologizers. Br J Psychiatry 1996; 168: 348-353.

Goldberg DP, Blackwell B. Psychiatric illness in general practice. A detailed study using a new method of case identification. Br Med J 1970; 1(707): 439-443.

Harpole LH, Williams JW Jr, Olsen MK et al. Improving depression outcomes in older adults with comorbid medical illness. Gen Hosp Psychiatry 2005; 27(1): 4-12.

Hays RD, Wells KB, Sherbourne CD et al. Functioning and well-being outcomes of patients with depression compared with chronic general medical illnesses. Arch Gen Psychiatry 1995; 52(1): 11-19.

Herzog T, Huyse FJ, Malt UF et al. Quality Assurance (QA) in consultation liaison psychiatry and psychosomatics (CL). Development and implementation of a European QA system. In: Bae AE, ed. European Union-Biomedical and Health Research. The BIOMED I Programme. Amsterdam: IOS Press 1995; 525-526.

Hospital Clínico Universitario. Memoria anual 2003. http://www.hcu-lblesa.es/mem2003/lblesa/index_actividad_global.html [date of access: may 2005].

Huyse FJ, Herzog T, Malt UF et al. The European Consultation-Liasion Workgroup (ECLW) collaborative study I; General Outline. Gen Hosp Psychiatry 1996; 18(1): 4455.

Huyse FJ, Herzog T, Lobo A et al. Detection and treatment of mental disorders in general health care. Eur Psychiatry 1997; 12(2): 70-78.

Huyse FJ, Lyons JS, Stiefel FC et al. "INTERMED": a method to assess health service needs. I. Development and reliability. Gen Hosp Psychiatry 1999; 21(1): 39-48.

Huyse FJ, de Jonge P, Slaets JP et al. COMPRI-an instrument to detect patients with complex care needs: results from a European study. Psychosomatics 2001; 42(3): 222-228.

Katon W, Gonzales J. A review of randomized trials of psychiatric consultation liaison studies in Primary Care. Psychosomatics 1994; 35: 268-278.

Katzelnick DJ, Kobak, KA, Greist JH et al. Effect of primary care treatment of depression on service use by 
patients with high medical expenditures. Psychiatric Services 1997; 48(1): 59-64.

Kisely SR, Goldberg DP. Physical and psychiatric comorbidity in general practice. Br J Psychiatry 1996; 169: 236-242.

Koenig HG, Shelp F, Goli V et al. Survival and health care utilization in elderly medical inpatients with major depression. J Am Geriatr Soc 1989; 37(7): 599-606.

Koenig HG, George LK, Peterson BL et al. Depression in medically ill hospitalized older adults: Prevalence, characteristics, and course of symptoms according to six diagnostic schemes. Am J Psychiatry 1997; 154(10): 13761383.

Koenig HG, Kuchibhatla M. Use of health services by medically ill depressed elderly patients after hospital discharge. Am J Geriatr Psychiatry 1999; 7(1): 48-56.

Kukull WA, Koepsell TD, Inui TS et al. Depression and physical illnes among elderly general medical clinic patients. Journal of Affective Disease 1986; 10(2): 153162.

Lesperance F, Frasure-Smith N, Talajic M. Major depression before and after myocardial infarction: its nature and consequences. Psychosom Med 1996; 58(2): 99-110.

Linn BS, Linn MW, Gurel L. Cumulative Illness Rating Scale. J Am Geriatr Soc 1968; 16: 622-626.

Lipowski ZJ. Review of consultation psychiatry and psychosomatic medicine 1. General principles. Psychosom Med 1967; 29: 153-171.

Lobo A, Ezquerra J, Gómez Burgada F et al. El "MiniExamen Cognoscitivo": un test sencillo, práctico, para detectar alteraciones intelectivas en pacientes médicos. Actas Luso Españolas de Neurología, Psiquiatría y Ciencias Afines 1979; 7(3): 189-202.

Lobo A. Philosophical humanism and empirical science: Spanish perspectives on Psychosomatics. In: Temoshock L., Fox B.H. eds. Special International Issue, Advances. Institute for the Advancement of Health 1986; 58-76.

Lobo A. Mental Health in Primary Care and in General medical clinics. In: Goldberg D and Tantam D, eds. Social Psychiatry and Public Health. New York: Lewiston 1990; 42-50.

Lobo A, Campos R, Pérez-Echeverría MJ et al. A new interview for the multiaxial assessment of psychiatric morbidity in medical settings. Psychol Med 1993; 23(2): 505510.

Lobo A, Montón C, Campos R et al. In: Luzan SA, ed. Detección de Morbilidad Psíquica en la Práctica Médica: El Nuevo Instrumento E.A.D.G. España: Roche 1994.
Lobo A, Campos R. Managing the Psychiatry/Primary Care interface. In: Robertson M, Katona C, eds. Depression and Physical Illness. John Wiley \& Sons Ltd 1996; 39-66.

Lobo A, Campos R. The contribution of epidemiology to psychosomatic medicine. Epidemiologia e Psichiatria Sociale 1997; 6(1): 40-47.

Lobo A, Saz P, Marcos G et al. Revalidación y normalización del Mini-Exámen Cognoscitivo (primera versión en castellano del Mini-Mental Status Examination) en la población general geriátrica. Med Clín (Bar) 1999; 112(20): 767-774.

Lobo A, Campos R, Valdés $\mathrm{M}$ et al. El proyecto multinacional europeo y multicéntrico español de mejora de calidad asistencial en Psiquiatría de Enlace en el Hospital General: Fundamentos y metodología general. Cuadernos de Medicina Psicosomática y Psiquiatría de Enlace 2000; 55-56: 51-61.

Lobo E, Bellido M, Campos R et al. Primera validación en español del método INTERMED: Un sistema de temprana detección de problemas biopsicosociales y de consumo de servicios en pacientes médico-quirúrgicos. Cuadernos de Medicina Psicosomática 2003; 67/68: 8998.

Lobo A, REPEP Network. Co-morbid depression in medical in-patients: the state of the multicenter study of the Spanish Liaison Network. Royal College of Psychiatrists. Section of Liaison Psychiatry Annual Conference. Barcelona, 2005.

Loughlin A. Depression and social support: effective treatments for homebound elderly adults. J Gerontol Nurs 2004; 30(5): 11-15.

Lozano M, Lobo A. An Spanish proposal for a new denomination: "Psychosomatic Psychiatry". J Psychosom Res (in press).

Lyness JM, King DA, Conwell Y et al. Self-rated health, depression, and one-year health outcomes in older primary care patients. Am J Geriatr Psychiatry 2004; 12(1): 110113.

Malt UF, Robak OH, Madsbu HP et al. The Norwegian naturalistic treatment study of depression in general practice (NORDEP)- I: A randomized double blind study. BMJ 1999; 318: 1180-1184.

Manning WG, Wells KB. The effects of psychological distress and psychological well-being on use of medical services. Med Care 1992; 30: 541-553.

Martucci M, Balliestrieri M, Bisoffi G et al. Evaluating psychiatric morbidity in a general hospital: a two-phase epidemiological study. Psychol Med 1999; 29: 823-832. 
Mayfield D, Mcleod G, Hall P. The CAGE questionnaire: validation of a new alcoholism screening instrument. Am J Psychiatry 1974; 131: 1121-1123.

Mayou R, Hawton K. Psychiatric Disorder in the General Hospital. Br J Psychiatry 1986; 149: 172-190.

McCusker J, Cole M, Dendukuri N et al. Delirium in older medical inpatients and subsequent cognitive and functional status: a prospective. CMAJ $2001 \mathrm{Sep} 4$; 165(5): 575-583.

Meyer T, Klemme H, Herrmann-Lingen C. Prevalence and effects of depressive and anxiety symptoms in internal medicine inpatients during the first year after hospital discharge. Z Psychosom Med Psychother 2002; 48(2): 17491.

Noel PH, Williams JW Jr, Unutzer J et al. Depression and comorbid illness in elderly primary care patients: impact on multiple domains of health status and wellbeing. Ann Fam Med 2004; 2(6): 555-562.

Ormel J, Costa e Silva JA. The impact of psychopathology on disability and health preceptions. In: Ustün BT, Sartorius N, eds. Mental Illness in General Health Practice: An International Study. Chichester: Willey 1995; 335346.

Ormel J, Vonkorff M, Oldehinkel AJ et al. Onset and disability in depressed and non-depressed primary care patients. Psychol Med 1999; 29: 847-853.

Pérez-Echeverría MJ. Correlaciones entre Trastornos Endocrinológicos, Niveles Hormonales en Sangre, Variables de Personalidad y Alteraciones Psicopatológicas. PhD Thesis, University of Zaragoza; 1985.

Prieto L, Alonso J, Ferrer M et al. Are results of the SF36 Health Survey and the Nottingham Health Profile similar? A comparison in COPD patients. J Clin Epidemiol 1997; 50(4): 463-473.

Rodin GM, Nolan RP, Katz MR. Depression. In: Levenson JL, ed. Textbook of Psychosomatic Medicine. Washington: American Psychiatric Publishing 2005; 193-217.

Ronalds C, Creed F, Stone K et al. Outcome of anxiety and depressive disorders in primary care. Br J Psychiatry 1997; 171: 427-433.

Rundell JR, Wise TN. Consultation-Liaison Psychiatry research. In: Rundell RJ, Wise MG, eds. Textbook of Consultation-Liaison Psychiatry. Washington D.C.: The American Psychiatric Press 1996; 207-226.

Saravay S, Pollack S, Steinberg MD et al. Four-year follow-up of the influence of psychological comorbidity on medical rehospitalization. Am J Psychiatry 1996; 153(3): 397-403.

Sartorius N, Ustün BT, Costa e Silva JA et al. An international study of psychological problems in primary care:
Preliminary report from the WHO collaborative project on psychological problems in general health care. Arch Gen Psychiatry 1993; 50: 819-824.

Savoca E. Psychiatric comorbidity and hospital utilization in the general medical sector. Psychol Med 1999; 29: 457-464.

Saz P, Launer LJ, Día JL et al. Mortality and mental disorders in a Spanish elderly population. International Journal Geriatric Psychiatry 1999; 14(12): 1031-1038.

Schneider G, Kruse A, Nehen HG et al. The prevalence and differential diagnosis of subclinical depressive syndromes in inpatients 60 years and older. Psychother Psychosom 2000; 69(5): 251-260.

Shmuely Y, Baumgarten M, Rovner B et al. Predictors of improvement in health-related quality of life among elderly patients with depression. Int Psychogeriatr 2001 ; 13(1): 63-73.

Simon G, Goldberg D, Tiemens BG et al. Outcomes of recognized and unrecognized depression in an International Primary Care Study. Gen Hosp Psychiatry 1999; 21: $97-$ 105.

Slaets JPJ, Kauffmann, RH, Duivenvoorden HJ et al. A randomized trial of geriatric liaison intervention in the elderly medical inpatients. Psychosom Med 1997; 59: 585591.

Smith FA, Querques J, Levenson JL et al. Psychiatric Assessment and Consultation. In: Levenson JL, ed. Textbook of Psychosomatic Medicine. Washington: American Psychiatric Publishing 2005; 3-14.

Spinhoven PH, Ormel J, Sloekers PPA et al. A validation study of the Hospital Anxiety and Depression Scale (HADS) in different groups of Dutch subjects. Psychol Med 1997; 27: 363-370.

Suh T, Gallo J. Syptom profiles of depression among general medical service users compared with specialty mental health users. Psychol Med 1997; 27: 1051-1063.

Tejero A, Guimera EM, Farré JM et al. Uso clínico del HAD (Hospital Anxiety and Depression Scale) en población psiquiátrica: un estudio de su sensibilidad, fiabilidad y validez. Revista del Departamento de Psiquiatría, Facultad de Medicina de Barcelona 1986; 13: 233238.

The EuroQoL Group. EuroQoL-a new facility for the measurement of health-related quality of life. Health Policy 1990; 16(3):199-208.

Tiemens BG, Ormel J, Jenner JA et al. Training primary-care physicians to recognize, diagnose and manage depression: does it improve patients outcome? Psychol Med 1999; 29: 833-845. 
Ustün BT. WHO Collaborative Study: an epidemiological survey of psychological problems in general health care in 15 centers worldwide. Int $J$ Psychiatry 1994; 6: 357-363.

Ustün BT, Sartorius N. Mental Illness in General Health Practice: An International Study. Chichester: Wiley; 1995.

Valdés M, de Pablo J, Campos R et al. El proyecto multinacional europeo y multicéntrico español de mejora de calidad asistencial en Psiquiatría de Enlace en el Hospital General: el perfil clínico en España. Med Clin (Bar) 2000; 115(18): 690-694.

Von Korff M, Ormel J, Katon W et al. Disability and depression among high utilizers of health care. A longitudinal analysis. Arch Gen Psychiatry 1992; 49(2): 91-100.

Von Korff M, Katon W, Bush T et al. Treatment costs, cost-offset and cost-effectiveness of collaborative management of depression. Psychosom Med 1998; 60: 143-149.

Ware JJ, Sherbourne CD. The MOS 36-item short-form health survey (SF-36). I. Conceptual framework and item selection. Med Care 1992; 30:473-83.

Wells KB, Golding JM, Burnam MA. Psychiatric disorder in a sample of the general population with and without chronic medical conditions. Am J Psychiatry 1988; 145: 976-981.

Wells K, Sherbourne C, Schoenbaum M et al. Five-year impact of quality improvement for depression: results of a group-level randomized controlled trial. Arch Gen Psychiatry 2004; 61(4): 378-386.

Williamson GM, Schulz R. Physical illness and symptoms of depression among elderly outpatients. Psychol Aging 1992; 7(3): 343-351.

WONCA (World Organization of National Colleges Academies and Associations of General Practice/family Physicians). ICHPPC-2 Defined (International Classification of health problems in Primary Care). $3^{a}$ ed. Oxford: Oxford University Press; 1985.

World Health Organization. International Statistical Classification of Diseases and Related Health Problems, $10^{\text {th }}$ Revision. Geneva: World Health Organization; 1992.

Wulsin LR, Vailant GE, Wells V. A systematic review of the mortality of depression. Psychosom Med 1999; 61: 617.

Zigmond AS, Snaith RP. The Hospital Anxiety and Depression Scales. Acta Psychiatr Scand 1983; 67: 361370.

Address for correspondence:

Antonio Lobo, MD.

Servicio de Psiquiatría, Hospital Clínico Universitario, pta. 3

Avda. San Juan Bosco, 15

50009 ZARAGOZA

SPAIN

e-mail: alobo@unizar.es 